\title{
LUT
}

University

\section{Power transmission and distribution losses - A model based on available empirical data and future trends for all countries globally}

Sadovskaia Kristina, Bogdanov Dmitrii, Honkapuro Samuli, Breyer Christian

This is a Final draft

version of a publication

published by Elsevier

in International Journal of Electrical Power \& Energy Systems

DOI: $10.1016 / j . j$ jepes.2018.11.012

Copyright of the original publication: () 2018 Elsevier Ltd.

Please cite the publication as follows:

Sadovskaia, K., Bogdanov, D., Honkapuro S., Breyer, C. (2019). Power transmission and distribution losses - A model based on available empirical data and future trends for all countries globally. International Journal of Electrical Power \& Energy Systems, vol. 107, pp. 98-109. DOI: https://doi.org/10.1016/j.ijepes.2018.11.012.

This is a parallel published version of an original publication. This version can differ from the original published article. 


\section{Power Transmission and Distribution Losses - A Model Based on Available Empirical Data and Future Trends for All Countries Globally}

Kristina Sadovskaia, Dmitrii Bogdanov, Samuli Honkapuro, Christian Breyer

Lappeenranta University of Technology, Skinnarilankatu 34, 53850 Lappeenranta, Finland, E-mail: Kristina.Sadovskaia@lut.fi, Dmitrii.Bogdanov@lut.fi, Samuli.Honkapuro@lut.fi,

\section{Christian.Breyer@lut.fi}

\section{Highlights}

- Power losses in transmission and distribution grids could be estimated

- Metrics for all countries of the world including economical, geographical and technical parameters

- Global power losses tend to decrease in the time

- Projection of power losses in grids for all countries till 2050 depending on set assumptions

\section{Keywords}
Power losses; power grids; forecasting; model description

\section{Abstract}

This article aims at the creation of a holistic and analytic function for describing the transmission and distribution (T\&D) grid power loss for all countries globally based on economical, geographical, political and technical available data. The created function is the very first of its kind, it is statistically well validated, and several examples are discussed. The function based on empirical data describes the dependence of the T\&D grid power loss level on widely available metrics, such as GDP per capita, corruption perception index, area of the country, temperature, grid organization parameter and level of urbanization. The same function can also be used by modellers to anticipate the development of the T\&D grid power loss in the years and decades to come. The suggested methodology could be easily reproduced and tuned to precise environmental conditions, what can be helpful for research in countries without available data.

\begin{tabular}{l|l}
\hline NOMENCLATURE & \\
ANN & Artificial Neural Networks \\
CPI & Corruption Perception Index \\
FA & Firefly Algorithm \\
GA & Genetic Algorithm \\
GDP & Gross Domestic Product \\
HV & High Voltage \\
LR & Linear Regression \\
LV & Low Voltage \\
\hline
\end{tabular}




\begin{tabular}{l|l}
\hline MV & Medium Voltage \\
$P L$ & Power Loss \\
PPP & Purchasing Power Parity \\
T\&D & transmission and distribution \\
\hline
\end{tabular}

\section{Introduction}

Among many characteristics of power networks, power loss is of utmost importance. The grid is aimed to transfer energy from sites of generation to the demand side, and power loss describes how efficient a grid system is in total. Mainly, technical losses appear while energy is transported through power lines, transformers and other equipment plus non-technical losses in some countries (energy theft) [1]. The technical losses have various reasons for their origin and development, and various ways to be calculated.

Technical power losses can be divided into two main categories:

1) Power line losses: These power losses depend on the conductivity of the line material, the cross-sectional area, the length of line [2] and further dynamically changing conditions, such as ambient temperature and current density in the conductor [3].

2) Transformer losses: There are two kinds of losses. No-load losses (fixed losses) occur permanently for all hours of a year as a consequence of the grid equipment. They are called iron losses and their appearance is due to magnetization currents which take place in transformers and reactors. For example, there are losses due to hysteresis and eddy currents in the iron core. These losses do not depend on the amount of current that flows through the transformer, but they could rise with the value of input voltage. Load losses (copper losses) are those which are caused by the flow of current through transformer windings and other parts of the equipment, and their magnitude depends on the amount of current flowing through conductors and its temporal resolution. In addition, magnetic flux leakage also takes place in transformers [2]. of all generation, and losses exceeding these levels are expected to be non-technical losses in the system.

The level of voltage in grids is also of utmost importance for the determination of power losses. A higher voltage level means that less current is needed to transmit the same amount of power through the network, and losses are proportional to the square of the current. However, a higher voltage level leads also to higher building costs of the network. Moreover, the loss factor increases depending on the remoteness of end-users from generators. Here, calculated power losses cover the total loss from high voltage (HV) to low voltage (LV) so that three loss fractions (HV, medium voltage (MV) and LV) are taken into account. 

of electricity that can cover all demand, including power losses. However, the factor of power loss adds some uncertainty, among others, in the system, and it becomes more difficult to predict the electricity that should be generated in the long-term, which increases the level of complexity of the power system design. Furthermore, network capacity is needed to transmit power losses from generators to loads via lines and transformers, in which losses occur. Thus, due to the losses, higher generating and network capacities have to be installed, which results in higher electricity costs.

Apart from the technical parameters, it is also important to take economic considerations into account. Annual expenses for power losses consist of generating, transmitting and distributing costs. [2]. Eventually, optimization of the losses is the optimization of the costs, where a designer takes into account the costs for generating and transmitting extra power and energy for losses, and on the other hand, considers the added costs for increasing the dimensioning of the network equipment. Hence, the aim is typically not to strive for minimal losses, but for minimal costs.

The stakeholders of the energy system want to know the level of power losses and their related costs. The level of the power loss has an impact on the whole power system, and consequently on the whole society. Estimations of the future power loss can be key for the design of proactive development strategies on a country level. Vishwakarma et al. [7] stated that system operation improvement, including power losses, can be one of the determinant for the adoption of proactive strategies in the power sector. Information about possible future power losses is very important for decision makers, because it gives opportunity to estimate future electricity demand and peak load. Both electricity consumption trends and power losses define the changes of the total power demand in the system. This electricity demand and peak load are the key parameters for any modelling of the power system development, independently on the scale and the methodology of modelling, as shown for the case of Taiwan [8] and system dynamics modelling and for whole Northeast Asia [9] and linear programing.

Future power loss can be estimated in different ways. One way is to simulate the network operations using optimal power flow (OPF) methodology, for which several different realisations of the algorithm have been developed [10], [11], [12]. All these methods demand a description of the network topology, which is complicated or impossible in case of long-term estimation, and in case of real networks the complexity of calculations increases. Another drawback is that this calculation method estimates ideal power loss, however power loss is strongly affected not only by the system structure, but also by generation, DSO and TSO operation principles and an increasing number of prosumers [13]. 

way would be the derivation of trends, which follow years in the past, without taking into account additional future possible changes. The more years into the future the trend is approximated, the less accurate this method is. Usually, short-term prognoses are used [14], so there is need for a long-term estimation method.

Dortolina and Nardira [15] suggest that parameters such as levels of urbanization and corruption may have some influence on overall T\&D losses. Specifically, a greater number of feeder points, which could be used as a representation of urbanization, were found to result in lower grid losses. In addition, losses were observed to decrease after privatization of companies, leading to the idea that there was stricter control of electricity consumption and less external, illegitimate energy use of power. Nagayama [16] also made the hypothesis that $\mathrm{T} \& \mathrm{D}$ losses can reduce with economic growth, due to general improvement in the utilities operation, also it was observed that even with the same GDP power loss levels varied due to different development levels and failed policies. However, a more holistic method of analysis has not been illustrated in scientific literature.

The intention here is to develop a model which can describe the total power loss in the transmission and distribution grid based on empirical data. The model is then calibrated for statistical reasons for all countries for which data are accessible. In the framework of this research it was stated that worldwide available parameters should be used in such a way so as to have the most possible and reliable calibration in the present situation. Upon this one can then go on to future projections. The aim of this research is to find the dependence of electricity losses in transmission and distribution grids on parameters for which values and reliable future projections can be found for as many countries as possible. This prerequisite significantly decreases the available parameters, making it unnecessary to use all technical grid parameters.

\section{2. Methodology}

\section{2.1. Possible methods}

102 There are several possible methods to determine a multidimensional function for relating input parameters to output values of the power loss in transmission and distribution grids. The following mathematical approaches

104 can describe the problem well: firefly algorithm (FA) [17], genetic algorithm (GA) [17], artificial neural networks 105 (ANN) [18] and linear regression (LR) [19].

106 Under close observation, FA is based on the same logic as fireflies move towards the brightest firefly. If there are no fireflies, the base species will move in a random direction. The intensity of brightness is an indicator of the best fitting function. The developer of this algorithm is Xin-She Yang [17]. 
109 Genetic algorithms are used to solve problems with a complex search. GA uses the logic of natural selection.

110 It assumes an evolution and then presents the advanced product with an increased environmental adaptation to

111 define a more optimal structure and respective coefficients of the formula [17]. Unfortunately, both FA and GA

112 cannot guarantee an optimal status of the found solution due to the heuristic nature of these algorithms and unclear

113 stop criteria.

114 Artificial neural networks perform like biological neurons, which accept input values with some weight. These

115 values are then summed up with bias and then presented as a result [18]. With given parameters and result data,

116 we can train ANN and specify a set of weights to produce optimized results for any given dataset. However, such

117 ANN will not provide an analytical formula, and dependencies will be unclear.

118 In this research, given algorithms and ANN could not perform the appropriate result due to a lack of input data

119 on which the result could be checked, complex structure of training of the neural networks and difficulties in the

120 ability to provide a formula in a required way. These complex algorithms do not fit our requirement, to create a

121 simple to use tool based on a transparent calculation methodology.

122 Thus the linear regression method [19] was the first step towards the development of a holistic formula to 123 describe the transmission and distribution (T\&D) gird losses for all countries globally. Linear regression could at

124 first provide a draft of all factors finally needed, as well as their weights and coefficients. With already known

125 relations of relevant factors, it is possible to specify which dependencies should be included or excluded from an

126 empiric data based formula. Regression is the simplest mathematical approach dealing with many impact levers,

127 but being still practical for the given problem with an explicit output formula.

128 2.2. Pre-analysis

129 Data on annual power losses worldwide were taken from the World Bank and IEA [20], [21], [22]. Power

130 losses are very different for the various countries in the world, which are visualized in Fig. 1 and Fig. 2. 

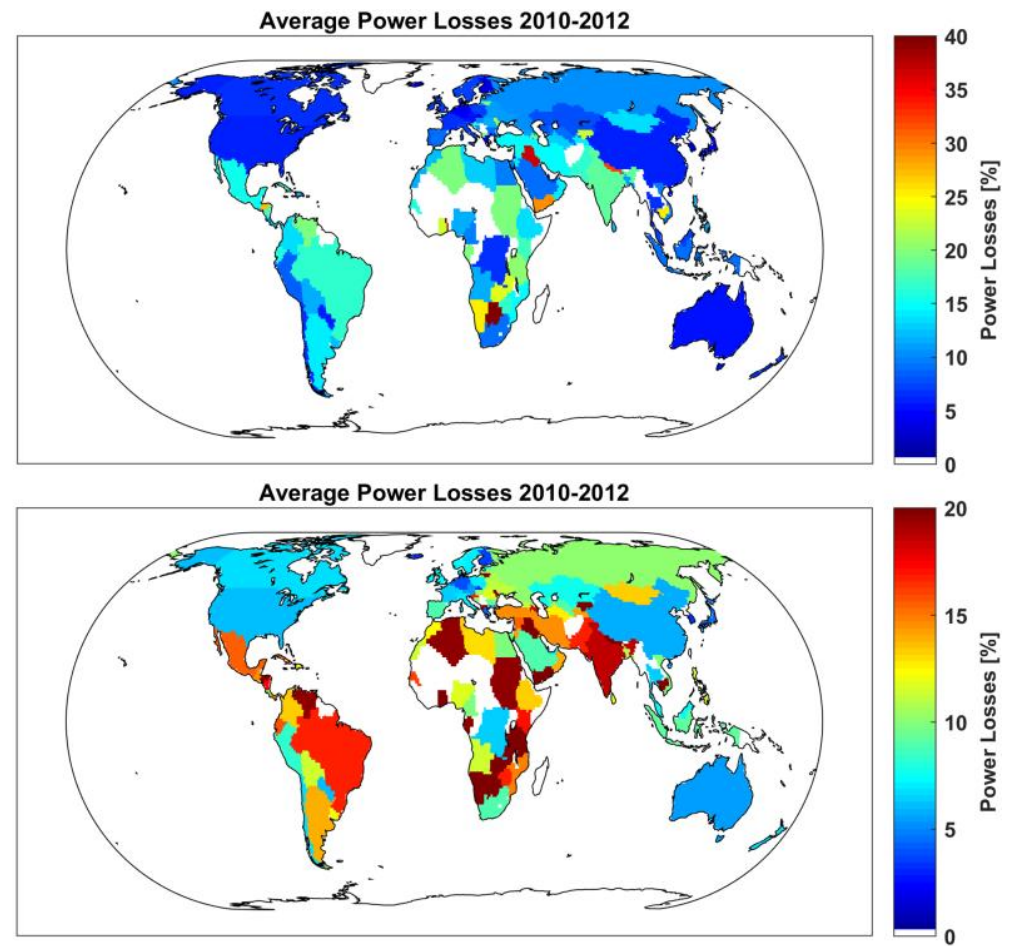

132 Fig. 1. Average power losses in T\&D grids for the years 2010 to 2012 in relation to total electricity generation worldwide in $0-40 \%$ (top) and $0-20 \%$ (bottom) scaling.

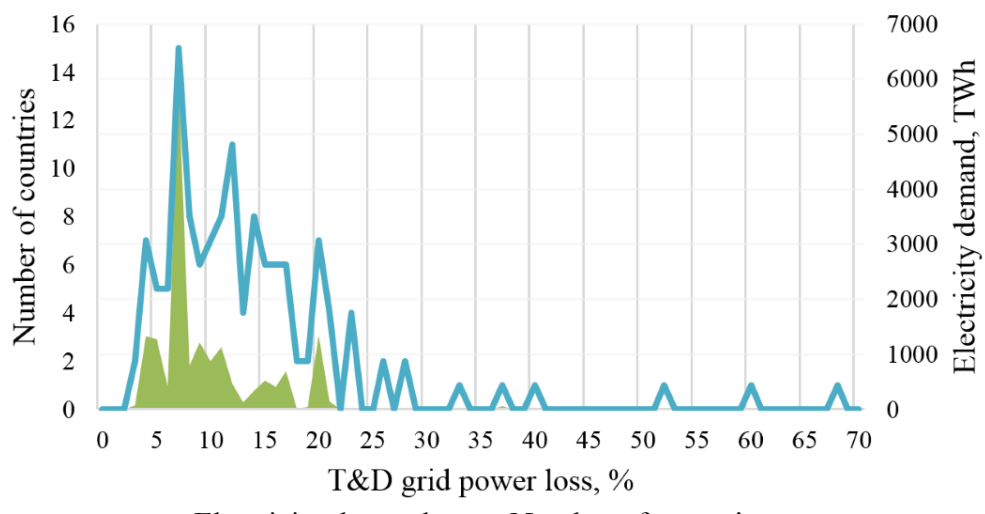

Electricity demand $\longrightarrow$ Number of countries

135 Fig. 2. Distribution of power losses in T\&D grids in relation to total electricity demand worldwide and the 136 number of countries with a certain power loss level for the years 2010 to 2012.

137 Based on World Bank data, power losses vary between around 3 and $70 \%$ of total electricity generation. Further 138 information about the countries in relation to their geographical, political and economic status, which probably affects losses, enable a first draft of influencing factors. As seen from Figs. 1 and 2, the lowest power loss is 140 observed in highly developed countries, with a high gross domestic product (GDP) per capita and well established power systems. Highest losses can be observed in countries of low income and high corruption.

142 For the very beginning, some possible and logical groups of parameters were combined. As a first step, parameters were included, such as: GDP per capita, corruption perception index (CPI), temperature, population 
144 density, level of urbanization and area of the country. These metrics can be found for almost all countries 145 worldwide, as well as their future projections.

146 Values and projections for population density, area of the country and GDP per capita are taken from World

147 Bank (GDP per capita [23], area of the country [24], population density [25]). Future projections for GDP per

148 capita till the year 2050 are based on the assumption that by the year 2100 GDP per capita should become equal

149 all over the world in order to fulfill the long-term Sustainable Development Goal of reducing inequality among

150 countries [26]. Urbanization level values are based on data provided by the United Nations [27]. Temperature data are taken from National Oceanic \& Atmospheric Administration (NOAA) [28]. Based on that dataset, the number

152 of days has been calculated when the average temperature exceeds $20^{\circ} \mathrm{C}$ - the normal operational temperature of the power lines [29]. Corruption perception index values are taken from Transparency International [30], where a

154 score of 0 means that a country is on a maximum level of corruption and a score of 10 means that there is no corruption in a country.

156 Future projections for CPI are based on the assumption that CPI is dependent on GDP per capita. It is assumed that this dependency has the form of a sigmoid like function in (1): at first GDP growth results in fast progress in

158 CPI increase, but further growth of GDP results in slower progress of CPI. CPI values for the year 2011 and their approximation by the sigmoid function are visualized in Fig. 3.

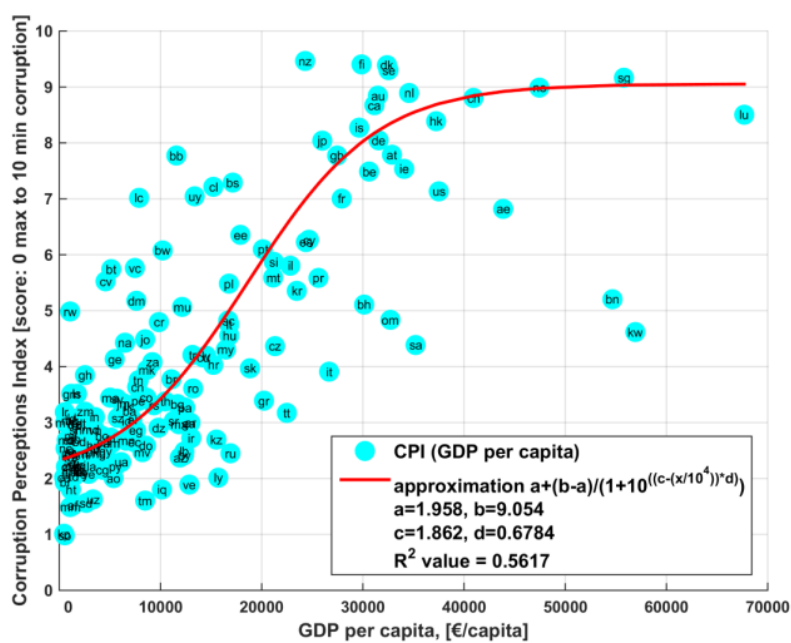

Fig. 3. Approximation line of CPI dependency on GDP per capita for the year 2011.

162 Equation (1) represents the dependence of CPI on GDP per capita for a certain country $\mathrm{j}$ and year i. This equation is used for estimating CPI for the years 2010 to 2050.

$$
C P I_{j i}=c_{1}+\frac{c_{2}-c_{1}}{\left.1+e^{\left(c_{3}-G D P\right.} j i\right) \cdot c_{4}}
$$



are the following:

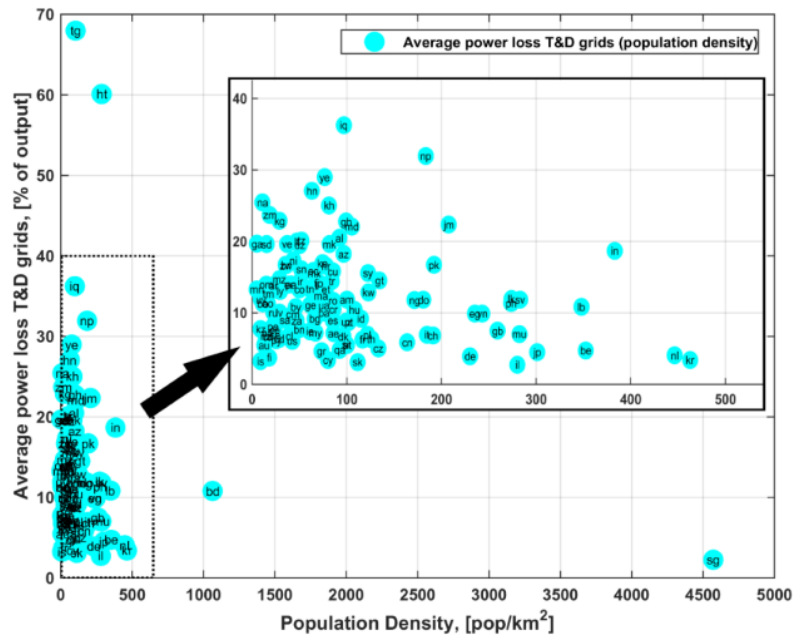

$170 \quad$ Fig. 4. Average power loss in T\&D grids in dependence on population density for the year 2011.

171 According to Fig. 4, it can be assumed that this dependency is weak or there is no dependency at all. However, 172 some countries, such as Singapore, which have the smallest average power loss, have the highest population 173 density. Among other countries, dependencies are slightly noticeable.

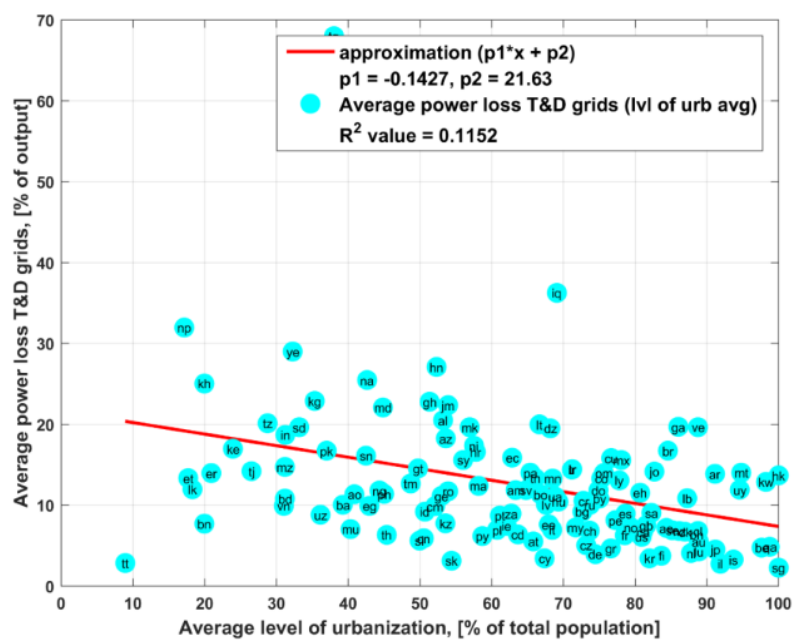

Fig. 5. Average power loss in T\&D grids in relation to average level of urbanization for the years 2010-2012.

The level of urbanization shows how many people live in urban areas compared to the total population of a country. Fig. 5 shows the correlation between urbanization level and power loss in T\&D grids: an increase in the level of urbanization of a country leads to a reduction in the power losses of T\&D grids. The spread of values is 
180 quite significant, but a trend can be stated for a decreasing linear dependency of the level of urbanization on the

181 T\&D grid losses.

182 3) Area of the country

183

184

185

186

187

188

189

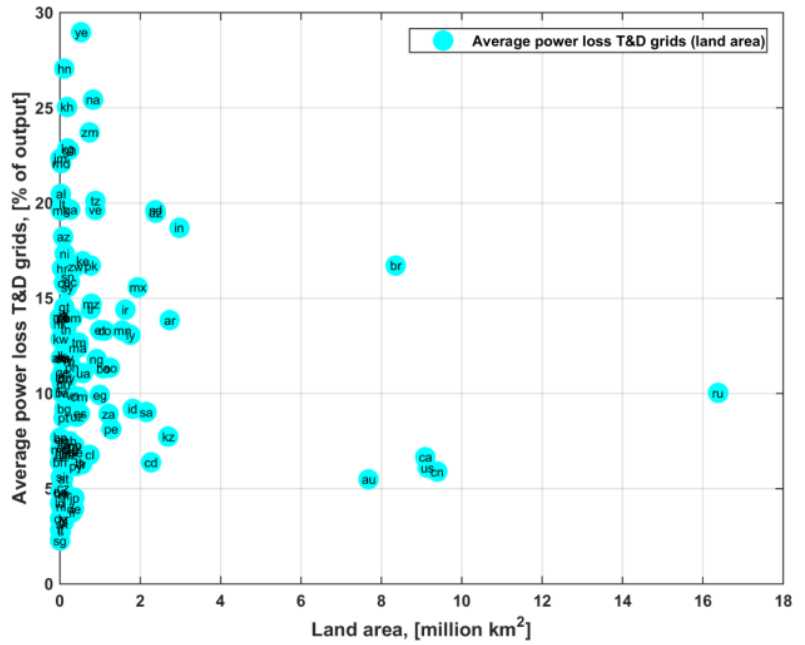
parameter.

4) GDP per capita

Fig. 6. Average power loss in T\&D grids in relation to country area diagram for the year 2014 .

Fig. 6 does not show a clear dependency of the T\&D grid losses on the land area of countries. Countries with a land area less than $1000000 \mathrm{~km}^{2}$ are the majority among all countries. This helps to set an assumption about a different gradation of T\&D grid power loss spreading in another area range or to determine limitations for this

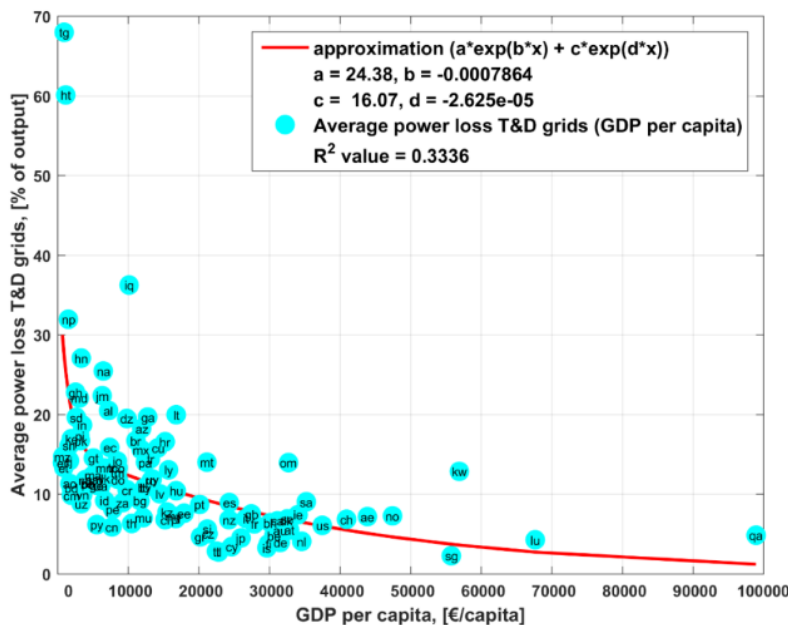

Fig. 7. Average power loss in T\&D grids in relation to average GDP per capita for years 2010-2012.

192 Fig. 7 shows the dependency of T\&D grid power loss on average GDP per capita, best described by a 193 composition of two exponential functions for different GDP per capital levels. GDP per capita helps to include the economic performance and productivity of a country into the analysis. 

and follows an exponential law (Fig. 7). However, there is almost no further decrease in power loss levels beyond

197 a GDP per capita threshold of about $40000 €$.

198 5) Corruption Perception Index

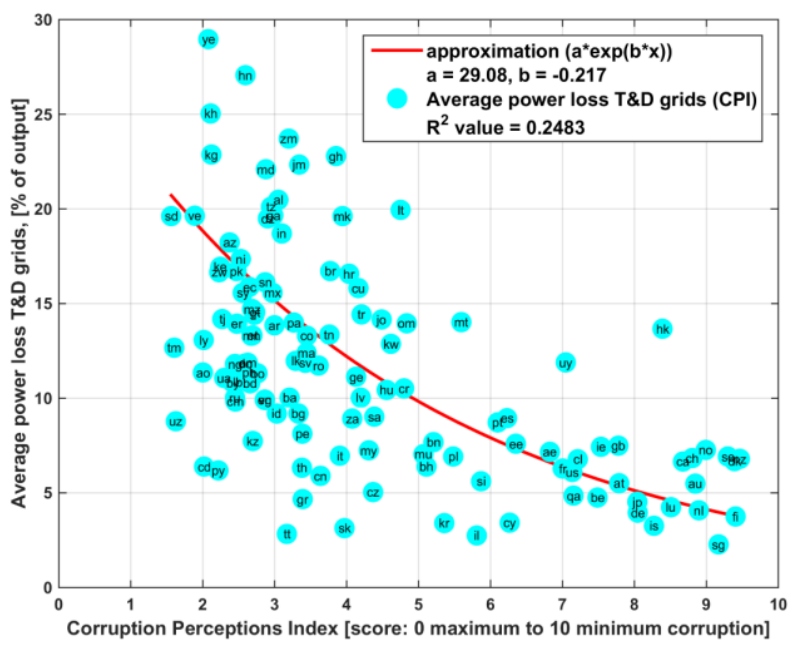

Fig. 8. Average power loss in T\&D grids in relation to Corruption Perceptions Index for the year 2011.

Corruption affects T\&D grid power losses in an exponential way at first approximation. For countries with higher corruption level figures, the average T\&D grid power losses are also higher than for countries, which are very close to a corruption free status (Fig. 8). From Fig. 8 it can be also seen that the distribution of the power that other influencing factors are more significant for those countries.

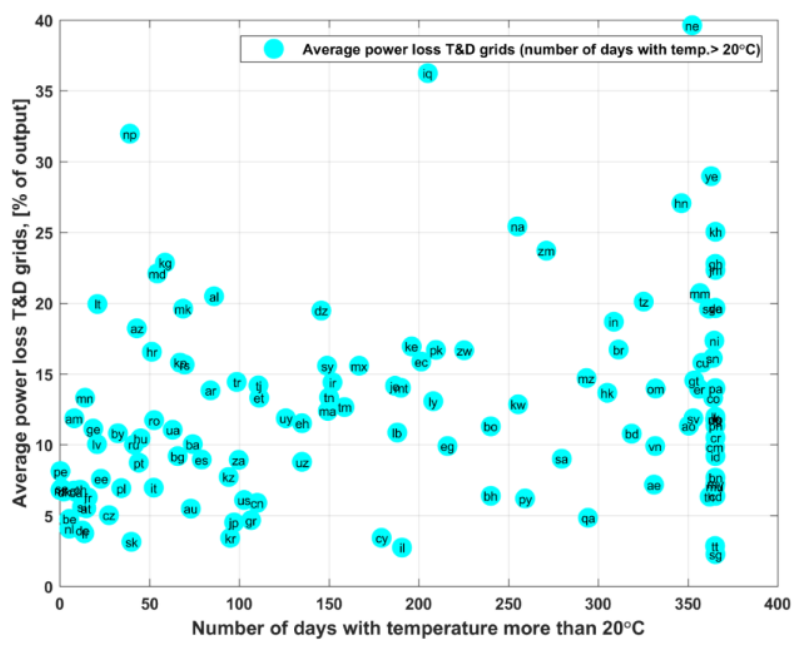

Fig. 9. Average power loss in $T \& D$ grids in relation to number of days with average temperature higher than 
Fig. 9 visualizes that the temperature level seems to have almost no influence on T\&D grid power losses.

211 However, a dependency could exist, but for the approximation in this research, other factors are much more 212 significant. For the data available for the year 2010 to 2012, the dynamics are as follows: for warmer years and 213 warmer climates, one can register a higher spread of observed losses in the system. This could imply that an effect 214 of temperature exists, however it is not as significant as GDP per capita or the corruption index, and should have 215 a lower weight in a final T\&D grid power loss estimation formula.

216 In order to check if the found dependencies have the same behaviour during the three years of available data, respective graphs (Fig. 10) for urbanization level and GDP per capita are created. The trend lines are slightly 218 different for the three different years, mainly due to the fact that approximations could be made with errors and some distortion takes place in the approximation lines of these years.
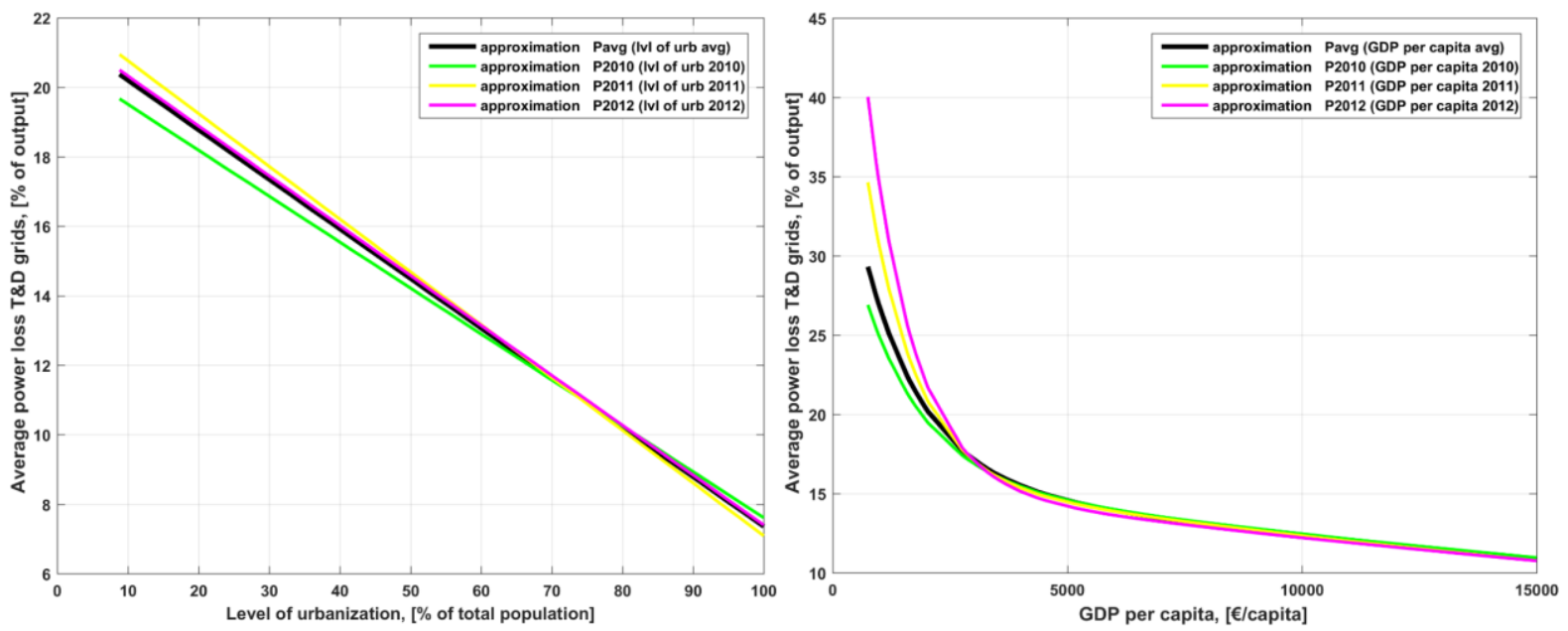

Fig. 10. Three approximation lines and average for power loss in T\&D grids in relation to the level of urbanization (left) and in relation to GDP per capita (right) for the years 2010 to 2012.

223 It is shown in Fig. 10 that the highest inter-year fluctuations are observed in countries with low levels of 224 urbanization and GDP per capita, in most cases this would represent least developed countries. For more highly developed countries the inter-year fluctuations are negligible, which means that in well-established power systems climate dependent parameters do not have a high impact on power losses in the system.

\subsection{Finite parameter range}

228 The selected parameters for establishing an empiric data based power loss function for T\&D grids are: GDP per capita, Corruption Perception Index, temperature, urbanization level, area of a country and organization of the grid. Due to the lack of available figures for the various countries, almost no data on the technical organization of the grid is included. The selected parameters include economic, geographic, climatic and political factors. 

description into account; therefore, a "grid organization" variable was added to the model. Moreover, parameters

234 driving other parameters were excluded. For example, GDP is transformed to GDP per capita, and number of people living in urban areas is transformed to the relative parameter, urbanization level. Eventually the influencing

236 factors describing T\&D grid power losses are depicted in Fig. 11.

237

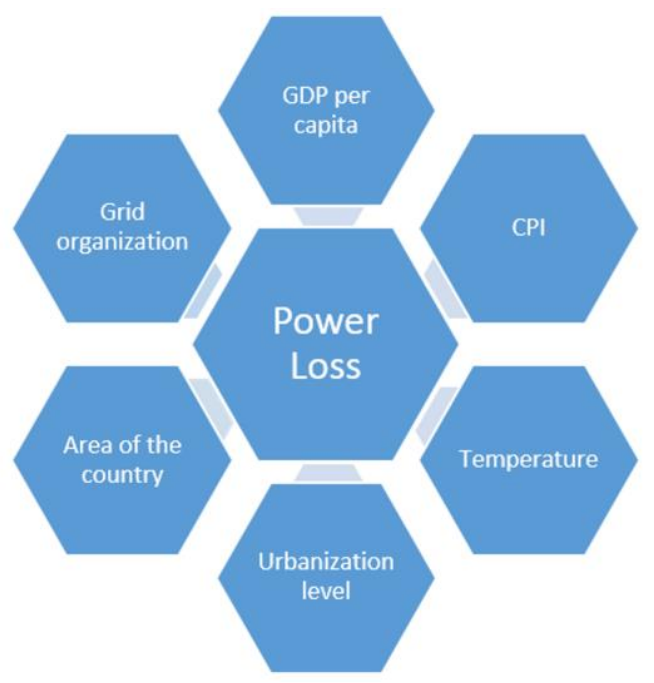

Fig. 11. Parameters which affect T\&D grid power loss level.

\subsection{Calibration and verification}

The key challenge is to determine the right combination of the introduced parameters and their interdependencies affecting T\&D grid power loss. As the main quality indicator, the value of the coefficient of determination (R-squared, $\mathrm{R}^{2}$ ) was selected. Improvements of the investigated target function were measured for their impact on the R-squared value. The coefficient of determination shows the total variation in relation to the mean value, i.e. the maximum value of $\mathrm{R}^{2}$ is 1 and the minimum is 0 , whereas the closer $\mathrm{R}^{2}$ is to 1 , the better the dataset matches the regression. In addition, another important quality factor had been established to track the number of countries (in percent of total) for which the error had been less than $20 \%$. Tests and visualization helped to identify which parameters and respective combinations are important to create a function that can represent the empiric data in the best possible way.

Besides the above mentioned parameters, some "noise data" was added to the initial dataset to increase the training set and to better prepare the formula for various changes in the list of parameters. The aim was to better ensure that the target function would not only find the best fitting curve for the obtained data, but would face real changes and return results which would not be inconsistent with the logic of future trends. This added robustness to the final formula. 


\section{Result}

256 Combining the requirements, the approaches and the key influencing factors on T\&D grid power loss $\left(P L_{j i}\right)$ of an arbitrary country $(j)$ for a given year $(i)$ is described by (2):

$$
\begin{aligned}
P L_{j i}=a_{0}+\left(b_{1} \cdot e^{d_{1} \cdot G D P_{j i}}+b_{2} \cdot e^{d_{2} \cdot G D P_{j i}}\right) & \\
\cdot & {\left[a_{1}+e^{d_{3} \cdot C P I_{j i}} \cdot\left(a_{2}+a_{3} \cdot \text { Area }_{j}\right)+a_{4} \cdot \text { Grid }_{j i}+a_{5} \cdot \text { GridFail }_{j i}+G D P_{j i} \cdot \text { Area }_{j}\right.} \\
\cdot & \left.\operatorname{ToC}_{j i} \cdot\left(a_{6}+a_{7} \cdot \text { Urb }_{j i}\right)\right]+e^{d_{3} \cdot C P I_{j i}} \\
\cdot & {\left[a_{8}+a_{9} \cdot G D P_{j i}+\text { Area }_{j} \cdot\left(a_{10}+a_{11} \cdot G D P_{j i}\right)\right] }
\end{aligned}
$$

Equation (2) represents the structure of the final T\&D grid power loss function. All coefficients and parameters are described as follows.

\subsection{Description of the result formula.}

Parameters and coefficients which establish the empirical data based formula are the following, including their dimensions: below; units; less than $15 \%$ in dimensionless units;

GridFail $l_{j i}$ : parameter representing the organizational level of the grid in the case of countries with power losses

273 higher than $15 \%$ in dimensionless units.

$274 \quad$ Coefficients:

$275 \quad a_{0}=3.6321$,

$276 a_{1}=0.99350654182$,

$277 \quad a_{2}=9.5276271680$,

$$
a_{3}=-9.7900659880 \cdot 10^{-5} 1 / \mathrm{km}^{2},
$$

$$
a_{4}=-0.30225330350,
$$




$$
a_{5}=-0.50687956705,
$$

$$
a_{6}=-9.0994145769 \cdot 10^{-13} 1 /\left(€ \cdot \mathrm{km}^{2} \cdot \mathrm{d} / \text { capita }\right),
$$

$$
a_{7}=2.0422451720 \cdot 10^{-14} 1 /\left(€ \cdot \mathrm{km}^{2} \cdot \mathrm{d} / \text { capita }\right),
$$

$a_{8}=-128.26282256$,

$$
a_{9}=2.2503543405 \cdot 10^{-3} 1 /(€ / \text { capita }),
$$

$a_{10}=1.4894050137 \cdot 10^{-3} 1 / \mathrm{km}^{2}$,

$$
a_{11}=-2.7299588274 \cdot 10^{-8} 1 /\left(€ \cdot \mathrm{km}^{2} / \text { capita }\right),
$$

$$
b_{1}=24.38 \text {, }
$$

$$
d_{1}=-7.864 \cdot 10^{-4} 1 /(€ / \text { capita }),
$$

$$
d_{2}=-2.625 \cdot 10^{-5} 1 /(€ / \text { capita }),
$$

$d_{3}=-0.217$.

\subsection{Explanation of numbers}

294 Initial years were taken from the World Bank, but further prognosis and development of data are based on the assumption that all countries will reach a GDP of $88000 € /$ capita in the year 2100 . This is based on the assumption that the leading countries in GDP per capita over the past 25 years set the reference of the average growth of GDP/capita and the other countries converge in a sigmoidal way to the reference in the year 2100 .

298 It can be seen from Fig. 7 that there is almost no change in the loss value as GDP per capita reaches the level of $40000 € /$ capita. Increase of GDP per capita beyond $40000 € /$ capita should not affect the T\&D grid power loss.

300 Consequently, a limitation for GDP per capita is $40000 € /$ capita.

$$
G D P_{j i}=0.5 \cdot G D P_{\text {orig } j i}+2 \cdot 10^{4}-\left|0.5 \cdot G D P_{\text {orig } j i}-2 \cdot 10^{4}\right|
$$

In (3) the original GDP per capita $\left(G D P_{\text {orig, }, j i}\right)$ is automatically limited to values which are further used in the formula.

For cases of countries with an area larger than $100000 \mathrm{~km}^{2}$, no further impact of the area on power losses was assumed. Hence, the maximum area was limited to $100000 \mathrm{~km}^{2}$ for all countries with area larger than that. Moreover, countries of very large area, such as Russia, Canada, Brazil and China, show the characteristic that only a small part is densely populated, and the rest of the area is more or less depopulated and not electrified. Thus, a limit of $100000 \mathrm{~km}^{2}$ was set. Input data in the formula should be corrected in this way to operate correctly. 
311 In (4) the original Area $\left(\right.$ Area $\left._{\text {orig }}\right)$ is automatically limited to values which are further used in the formula.

$312 U r b_{j i}:$ Annual percentage of population at mid-year residing in urban areas [27].

$313 C P I_{j i}$ : Corruption Perceptions Index CPI as a function of GDP per capita described in (1) [30].

$314 T T_{0} C_{j i}$ : Amount of days annually with a daily average temperature more than $20^{\circ} \mathrm{C}$ (in this research it is taken 315 as an average value for 3 years, but for better preciseness annual data may be better) [28].

316 Temperature with a value more than $20^{\circ} \mathrm{C}$ could have an effect on the resistance of cables, so that it has a direct 317 impact on power losses [31]. However, this factor should be predicted while the grid is planned, so lines will have 318 certain qualities to minimize the temperature impact. Nevertheless, some countries do not have precise control of 319 this factor.

320 The technological status of the grid is represented by two parameters: Grid $_{j i}$ and GridFail $_{j i}$.

$321 \quad$ Grid $_{j i}$ : Artificial parameter that shows the organization of the grid and operation effectiveness in the case of 322 countries for which losses in the initial reference years 2010 to 2013 are less than $15 \%$ (as this value is assumed 323 to be a top limit of the technical power losses [5]). This parameter has been produced by the analysis of two 324 available datasets: GDP per capita and power loss values.

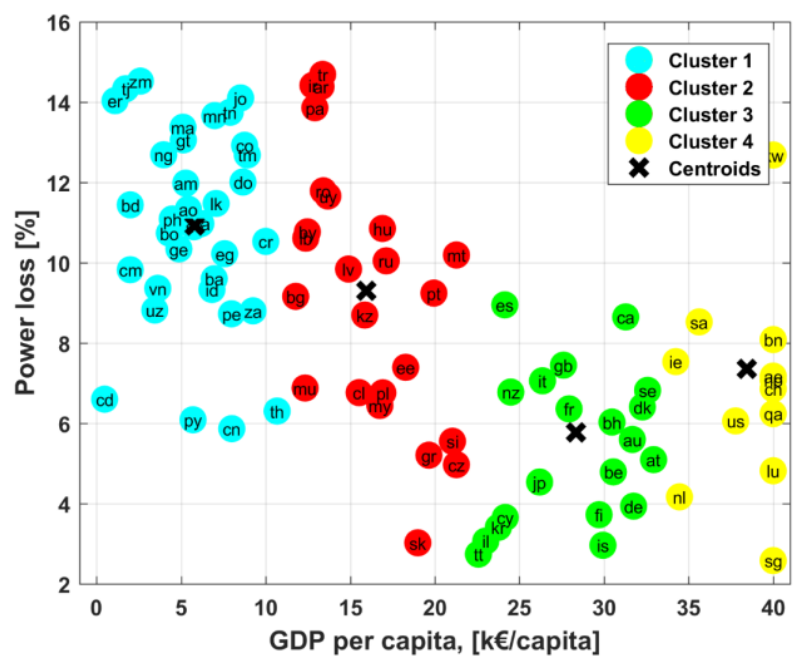

326 Fig. 12. Division of countries with power loss lower than $15 \%$ into 4 clusters with their centroids. Power loss 327 and GDP per capita values are averaged for all countries with an average power loss less than $15 \%$ for the years 2010-2013.

329 Based on GDP and power losses values, countries with T\&D grid power loss lower than $15 \%$ were allocated 330 to 4 clusters, (Fig. 12 and Table 1). The amount of clusters was chosen in order to reach the best distinction 
331 between the clusters, according to Euclidean distance to the cluster centroids. For each cluster the GDP and power

332 loss average values were calculated and the following division was applied:

333 Table 1.

334 Cluster division for Grid $j$ i.

\begin{tabular}{lccc}
\hline \hline $\begin{array}{l}\text { Name of } \\
\text { cluster }\end{array}$ & $\begin{array}{c}\text { Range of GDP/capita } \\
{[\mathrm{k} € / \text { capita }]}\end{array}$ & $\begin{array}{c}\text { Average GDP } \\
{[\mathrm{k} € / \text { capita }]}\end{array}$ & $\begin{array}{c}\text { Average T\&D grid } \\
\text { power loss [\%] }\end{array}$ \\
\hline Cluster 1 & $0-11$ & 5.8 & 10.9 \\
Cluster 2 & $11-22$ & 15.9 & 9.3 \\
Cluster 3 & $22-33$ & 28.3 & 5.7 \\
Cluster 4 & $33-40$ & 38.4 & 7.3 \\
\hline \hline
\end{tabular}

335

336 Assignment of weights according to the cluster average power loss:

3372 - power losses are less than the cluster average values of T\&D grid power loss for each cluster from Table 1

338 (There was no direct dependency of power losses on the type of electricity market found, but according to the

339 research, countries of this cluster usually have deregulated electricity market type and generation is close to

340 consumption centers.);

$341-$ power losses are in the limit of 1.0-1.4 of cluster average values of T\&D grid power loss for each cluster 342 from Table 1;

3430 - power losses are higher than 1.4 of the cluster average values of T\&D grid power loss for each cluster from 344 Table 1.

$345 \quad$ GridFail $_{j i}$ : Artificial parameter that shows the organization of the grid and operation effectiveness in the case

346 of countries for which losses are more than $15 \%$. The same approach for the parameter Grid $_{j i}$ has been used for

347 countries with a T\&D grid power loss higher than $15 \%$. Each was allocated to 3 different clusters according to

348 the Euclidean distance. The cluster separation is presented in Fig. 13 and Table 2. 


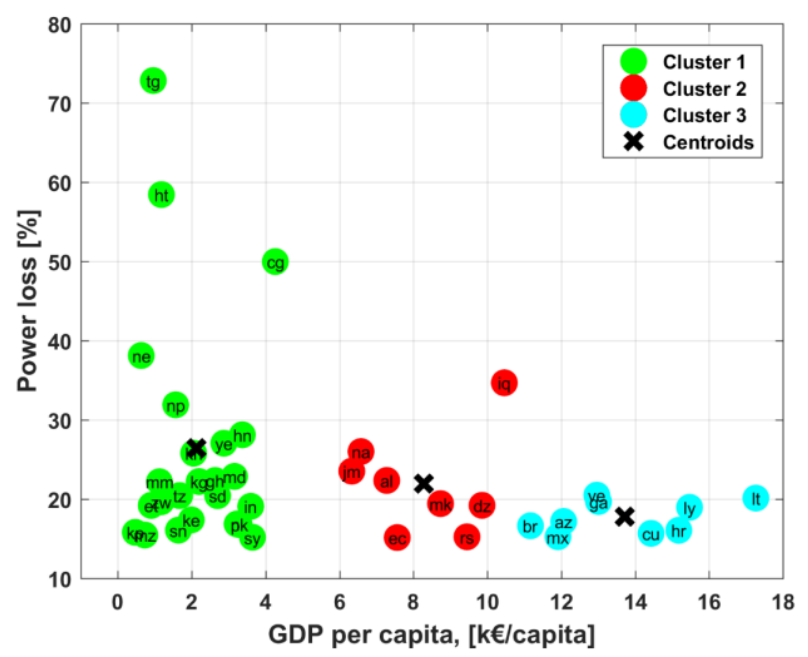

Fig. 13. Division of countries with power loss higher than $15 \%$ into 3 clusters with their centroids. T\&D grid for the years 2010-2013.

\section{Table 2.}

Cluster division for GridFail $j$.

\begin{tabular}{lccc}
\hline \hline $\begin{array}{l}\text { Name of } \\
\text { cluster }\end{array}$ & $\begin{array}{c}\text { Range of GDP/capita } \\
{[\mathrm{k} € / \text { capita }]}\end{array}$ & $\begin{array}{c}\text { Average GDP } \\
{[\mathrm{k} € / \text { capita }]}\end{array}$ & $\begin{array}{c}\text { Average T\&D grid } \\
\text { power loss [\%] }\end{array}$ \\
\hline Cluster 1 & $0-5$ & 2.1 & 26.4 \\
Cluster 2 & $5-11$ & 8.3 & 22.0 \\
Cluster 3 & $11-22$ & 13.7 & 17.8 \\
\hline \hline
\end{tabular}

356 Assignment of weights according to the cluster average power loss:

$357 \quad 1$ - power losses are less than the cluster average values of T\&D grid power loss for each cluster from Table $358 \quad 2$

3590 - power losses are higher than the cluster average values of T\&D grid power loss for each cluster from Table

2.

361 All countries with power losses higher than 19\% (1.25 of maximum technical power loss [5]) are assumed to 362 have a poor grid organization and the value of the GridFail $_{j i}$ parameter is set equal to zero.

363 These values are used to describe the grid organization for the year 2010. In the future it is very probable that 364 network infrastructure will be improved [32]. Coming from that assumption, it is assumed that, for the year 2050 grids with less than $15 \%$ T\&D grid power loss improve linearly according to the following rule: weight of 2 stays 

1 stays the same, weight of 0 improves to 1 .

368 The parameters Grid $_{j i}$ and GridFail $_{j i}$ are designed so that technological factors influencing the grid cannot be omitted. The parameters are flexible enough for this research, but may be determined more on a technological basis in future research.

Results for all countries and all data (figures for countries separately, continents and the world, interactive coloured matrixes) are presented in the Supplementary Material of this article so that results could be easily reproduced and analysed.

The result diagram for the world is shown in Fig. 14. To get a representative image of T\&D grid power losses in the world, all countries power loss values individually were converted from percent into absolute loss numbers and then aggregated to derive the worldwide T\&D grid power loss value.

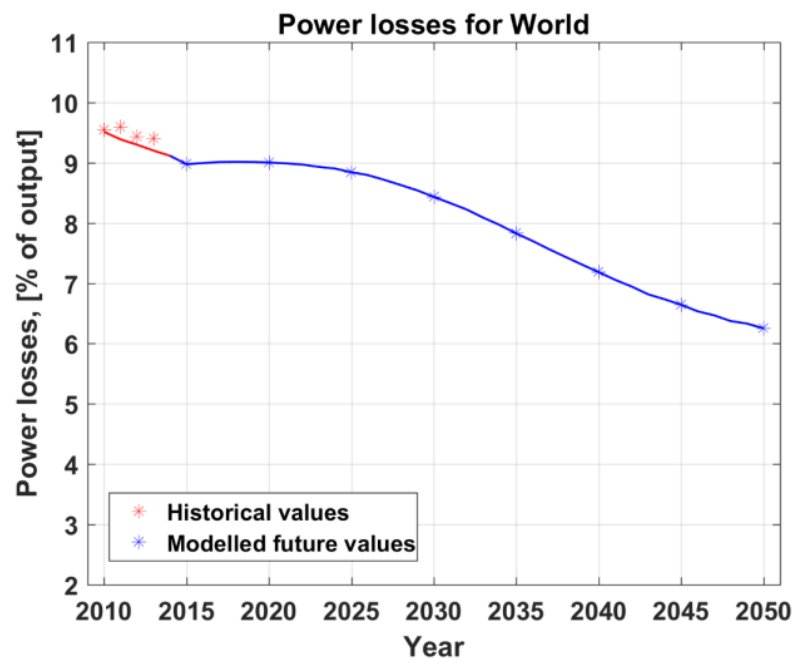

Fig. 14. T\&D grid power loss values for the years 2010 to 2013 (red stars) and simulated and projected with the equation (2) prognosis till the year 2050 (red and blue lines).

381 It was found, that the power loss value does not depend on the absolute value of electricity demand. Thus T\&D 382 grid power loss function does not require the electricity demand of countries in future years. However, for a weighting of countries to groups of regions, continents or the world a relation to the electricity demand is required.

384 Electricity demand data have been developed in three steps: Firstly, the global trend of electricity demand data from IEA [21], [22] is used. Secondly, trends for all countries separately were created. Thirdly, a weighted average value of countries from their individual value to the global average of a country of the respective GDP per capita level had been taken into account. 

2050 is around $6.5 \%$ of total generated electricity.

391 Verification is made by three indicators: R-squared value, histogram of residuals and amount of countries for 392 which the T\&D grid power loss of the official database and the calculated value by (2) differs by less than $20 \%$.

393 The final numbers, also available in the Supplementary Material, show the following quality:

- $\quad$ R-squared: $\mathrm{R}^{2}=0.93$

- Percentage of countries with projection deviation for the years 2010 to 2013 to the real value being less

- The histogram below suggests that the residuals for all countries have a normal distribution.

398

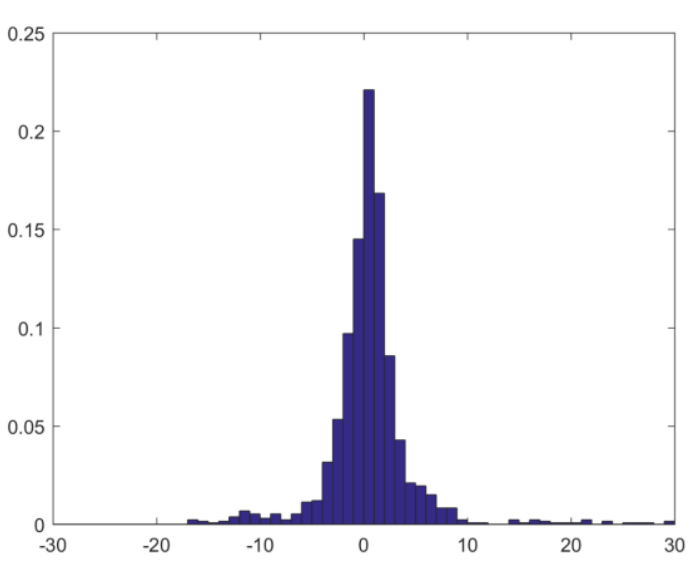

Fig. 15. Histogram of residuals for the calculated T\&D grid power loss values to the real data for all countries for the years 2010 to 2013 . The ordinate axis represents the frequency of a certain residual and the abscissa axis is in units of the T\&D power loss in absolute values.

The histogram shows the probability of a result error sorted into a certain interval of error values. As is depicted in the Fig. 15, the distribution is almost symmetrical around the zero of the ordinate axis. However, there is a slight difference in the shoulders. This could be explained by the variety of values and special countries which are out of the normal distribution. This graphical representation of the error allows the assumption that the majority of calculated estimations by (2), look empirically reliable.

R-squared, the calculated amount of countries matching the $20 \%$ error and the histogram are three main indicators, which document a reasonable good quality of the achieved results.

\subsection{Example of calculation}

Iran can act as an example for the calculation of the T\&D grid power loss estimate using (2) for the year 2025. Initial values for this certain case of Iran in the year 2025 are: 
$413 \quad$ Area ${ }_{\text {Iran }}: 1628550 \mathrm{~km}^{2}$;

$414 \quad U r b_{\text {Iran 2025: }} 77.8 \%$;

$415 \quad C P I_{\text {Iran 2025: }}$ 4.9;

416 To $C_{\text {Iran 2025: }} 147.8 \mathrm{~d}$;

417 Grid Iran 2025: 0.375;

418 GridFail Iran 2025: 1.

419 Coefficients $a_{0}-a_{11}, b_{1}-b_{2}$ and $d_{1}-d_{3}$ are presented in the section "Description of the result formula".

420 All values above are inserted into (2) by applying the parameters of Eq (2) and using Eqs. (3) and (4). After 421 calculating, the result is found: $P L_{\text {Iran } 2025}=12.7 \%$.

422 If the same calculation is repeated for the years from 2010 until 2050, the following power loss values 423 establishing the respective development of Fig. 16 can be created:

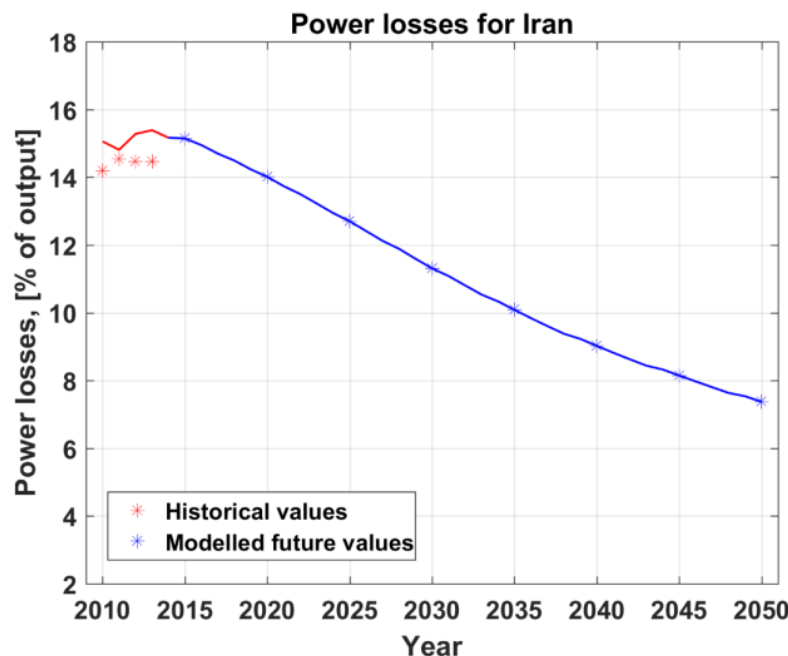

Fig. 16. Estimation of the T\&D grid power loss in Iran for the years 2010 to 2050 according to (2) and with real values for the years 2010 to 2013 .

427 Fig. 16 shows real historical values, taken from statistical documents [20] (red stars *), and the calculated values obtained by (2) (red and blue lines).

429 The trend is obviously positive, which means it can be expected that Iran will reduce T\&D grid power losses 430 in the years and decades to come. The power loss can be estimated to be about halved from now to the year 2050.

431 According to the formula, the T\&D grid power loss in 2010 was $15.06 \%$, and it is estimated to be in the year 2050 about 7.37\%: $\Delta P L_{2050 / 2010}=P L_{2050} / P L_{2010}=7.37 \% / 15.06 \%=0.489$. 


\section{Application and discussions}

434 As has been shown in the Results section for the case of Iran, the power loss function according to (2) provides 435 values which tend to decrease over time. To discuss the structure of the T\&D grid power loss function according to (2) in more detail, some specific cases are studied in this section.

437 Modelled power loss estimates for China provide a result that is almost 3.5\%abs higher than the one which is 438 presented in the official data source (Fig. 17). This special case seems to be the combination of two errors which 439 result in this significant difference. Apart from a possible mistake in projection calculation, the Chinese T\&D grid management could be better than it is estimated based on the global statistical average, in particular since the GDP per capita in the industrialized eastern parts of China is significantly higher than the country average. This leads to better grid management at least in the regions of highest electricity demand.

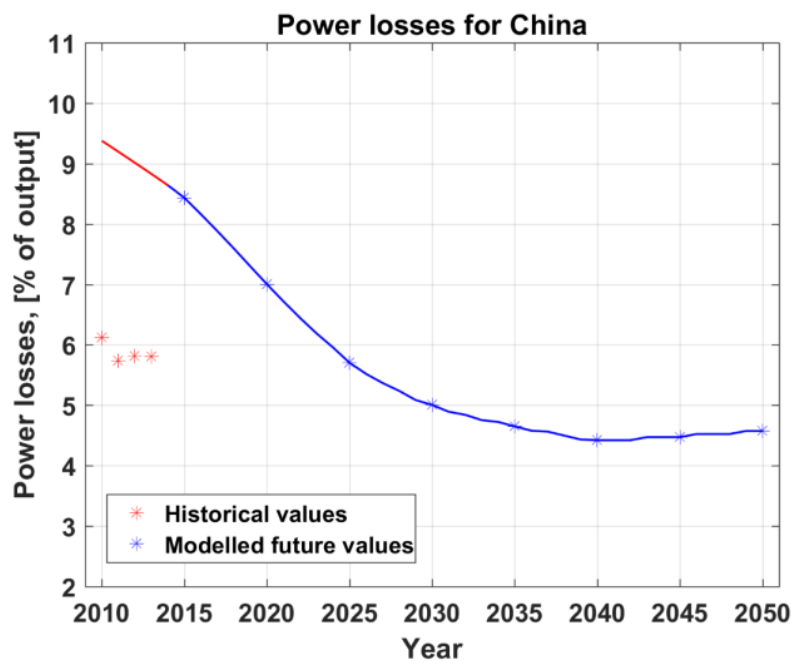

444 Fig. 17. Estimation of the T\&D grid power loss in China for the years 2010 to 2050 and comparison to the real historical values for the years 2010 to 2013.

446 Based on the parameters for calculating the T\&D grid power loss estimate, the power loss is $9.38 \%$ of electricity 447 generation. This is characterized by GDP per capita that starts from $7090 € /$ capita and a CPI initial value of almost

448 3. However, the organization of grid is assumed to be developed and further improvements are not needed.

449 The future development is assumed as follows: GDP per capita is expected to rise to its limit of $40000 € /$ capita 450 and CPI continues its growth to a value of 9. As a positive result of the strong increase in GDP per capita, the 451 power loss is expected to reach $4.58 \%$ in the year 2050 , so that the total estimated benefit is $9.38 \%-4.58 \%=$ $4524.8 \%$. In addition, if the counting were according to published values, the real benefit may be approximately $6 \%$ $453-4.6 \% \approx 1.4 \%$. In the case of China, the real power losses are not that high and lower than what could be expected due to the achieved level of GDP per capita and the CPI. 

loss value, the easier it can be reduced. Small values of losses, for example, 4-6\%, are very hard to change or improve, however values with $20 \%$ and more are much more open to reductions and developments.

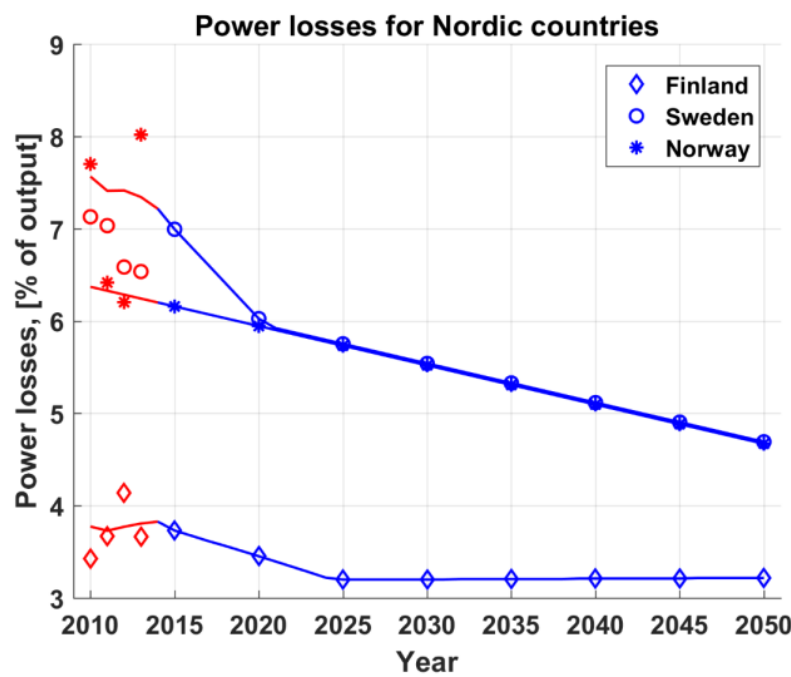

Fig. 18. Estimation of T\&D grid power loss in Finland, Sweden and Norway for the years 2010 to 2050. Blue colour represents modelled values and red colour historical ones.

463 The Nordic countries are characterized by their relatively flat decreasing T\&D grid power loss estimate. These countries are known for a relatively high GDP per capita and very low corruption level. Parameters are presented in Table 3.

\section{Table 3.}

467 Influencing parameters for Nordic countries.

\begin{tabular}{lccc}
\hline \hline $\begin{array}{l}\text { Name of parameter } \\
\text { (value of } 2010 \rightarrow \text { value of 2050) }\end{array}$ & Finland & Sweden & Norway \\
\hline GDP per capita, [k€/capita] & $29.6 \rightarrow 74.2$ & $32.3 \rightarrow 77.6$ & $47.3 \rightarrow 72.8$ \\
CPI & $7.9 \rightarrow 9.1$ & $8.3 \rightarrow 9.1$ & $8.9 \rightarrow 9.1$ \\
Grid organization, Grid ${ }_{\mathrm{ji}}$ & $2 \rightarrow 2$ & $0 \rightarrow 1$ & $0 \rightarrow 1$ \\
Urbanization level, [\%] & $83.6 \rightarrow 89.1$ & $85.1 \rightarrow 90.3$ & $79.1 \rightarrow 87.2$ \\
\end{tabular}


conditions are very similar. As well, CPI, GDP per capita and urbanization level have only very little differences.

In addition, the electricity market structure of these countries is very similar.

473 The difference in the T\&D grid power loss between Finland and the two other Nordic countries might be 474 explained by different grid cost optimization strategies, since slight variations in cost optimization of the grid 475 infrastructure could have a major impact on the T\&D grid power loss. If cost optimization is focused on capital expenditures, it could lead to slightly higher T\&D grid power losses. The T\&D grid optimization in Finland is focused on the total lifecycle cost, including capital expenditures, operational and maintenance expenditures and including T\&D grid power losses in the long-term [2]. This may lead to lower T\&D grid power losses in Finland, since the grid optimization explicitly includes the power losses.

As the GDP per capita in Finland reaches $40000 € /$ capita, the reduction in power losses stops. This happens for Sweden and Finland in the years 2020 to 2030. For Norway the GDP per capita stops its direct influence already at the very beginning, in the year 2010. Obviously, Finland has the best performance, leading to an excellent grid organization parameter. While Sweden and Norway still have some room for improvements. yet impossible to improve up to a zero percent loss in well organized and efficient grids [33]. selected and are presented in Fig. 19.

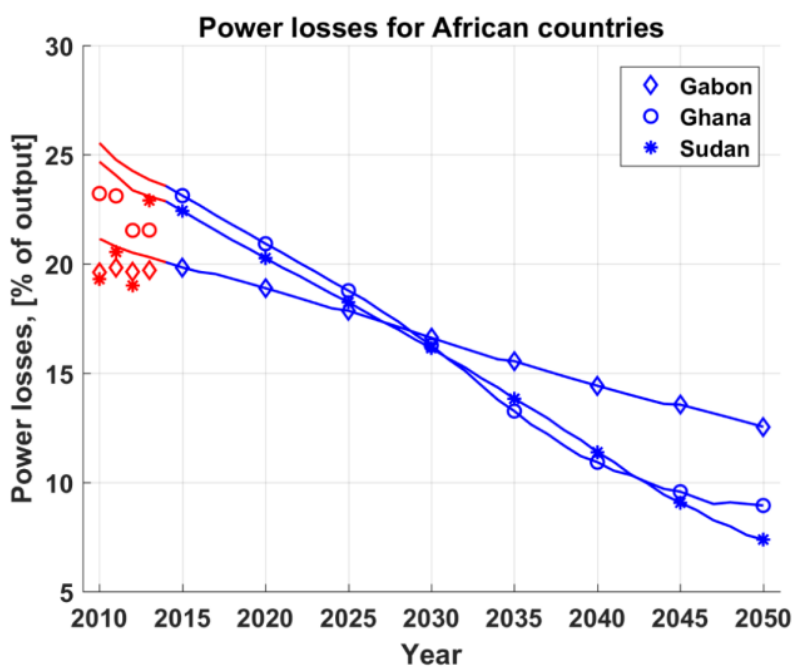

Fig. 19. Estimation of T\&D grid power loss in Gabon, Ghana and Sudan for the years 2010 to 2050. Blue colour represents modelled values and red colour historical ones. 

temperature is almost the same, and other parameters are presented below:

$494 \quad$ Table 4.

495 Influencing parameters for selected African countries.

\begin{tabular}{lccc}
\hline \hline $\begin{array}{l}\text { Name of parameter } \\
\text { (value of } 2010 \rightarrow \text { value of 2050) }\end{array}$ & Gabon & Ghana & Sudan \\
\hline GDP per capita, [k€/capita] & $12.3 \rightarrow 39.2$ & $2.3 \rightarrow 45.6$ & $2.4 \rightarrow 25$ \\
CPI & $3.9 \rightarrow 8.8$ & $2.5 \rightarrow 9$ & $2.5 \rightarrow 7.1$ \\
Grid organization, GridFail ${ }_{\text {ij }}$ & $0 \rightarrow 1$ & $0 \rightarrow 1$ & $0 \rightarrow 1$ \\
Urbanization level, [\%] & $85.7 \rightarrow 91$ & $50.7 \rightarrow 70.5$ & $33.1 \rightarrow 49.8$ \\
\hline \hline
\end{tabular}

496

The T\&D grid loss estimate developments can be explained as follows: While the GDP per capita increases, 498 the CPI increases as well, and the grid organization parameter has also a tendency to improve by one step.

499 In Fig. 19 it is shown that the loss development for Gabon is different compared to the two others countries.

500 Such a characteristic can be explained by two main factors: GDP per capita and urbanization level. Whenever the 501 urbanization factor is high, the length of distribution networks increases, a steep rise of GDP helps to compensate 502 for power losses (e.g. Ghana). In the case of Gabon, GDP does not hit the limit of $40000 € /$ capita, hence it could 503 be assumed that a highly urbanized country with not yet very high GDP per capita will decrease its power loss 504 lower.

505 It is assumed that with a respective increase of GDP, also investments into electrical grids will rise, and as a 506 result, technical losses will decrease. However, in this case it is not yet possible to improve the grids to as high a 507 level as had been possible for the Nordic countries. In general, the grids for the three selected African countries 508 become significantly more efficient, but not yet to the level achieved in Sweden, Norway and Finland.

509 A good example of the reason why country area of more than $100000 \mathrm{~km} 2$ does not have an impact on T\&D 510 grid power loss can be studied for the case of Russia (Fig. 20). 


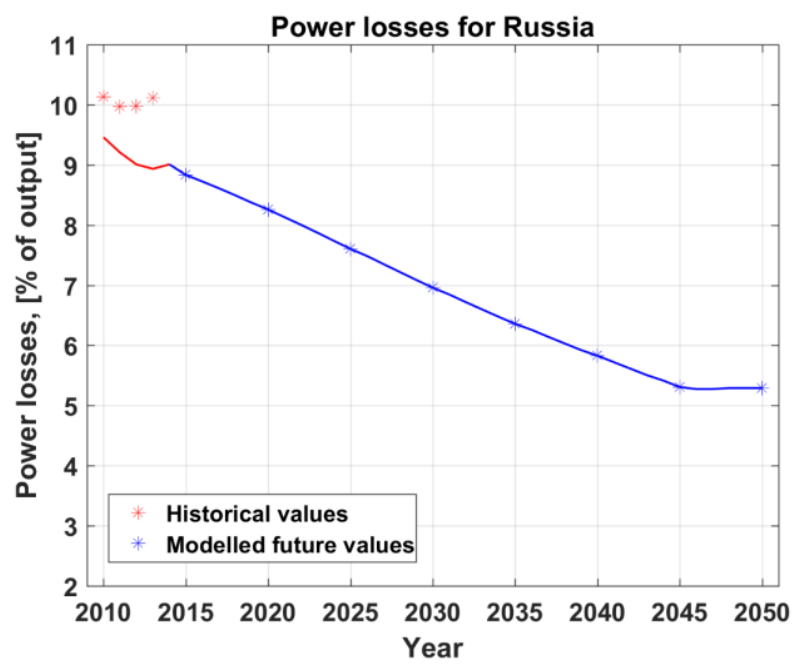

512 Fig. 20. Estimation of T\&D grid power loss in Russia for the year 2010 to 2050 and with real values for the 513 years 2010 to 2013.

514 The area of the Russian Federation is about 16.38 million $\mathrm{km}^{2}$. The limitation of the $100000 \mathrm{~km}^{2}$ area parameter 515 is valid in this case. The difference in effective area in (2) is obviously enormous, but the approximation line 516 shows a quite logical future trend.

517 The decrease in T\&D grid power loss is caused by an increase of GDP per capita (from $16.3 \mathrm{k} € /$ capita to 45.6

$518 \mathrm{k} € /$ capita) and CPI (from 4.9 to 8.95 ). Urbanization is expected to rise from $73.7 \%$ to $81.1 \%$, which does not have 519 a significant influence on the total T\&D grid power loss trend line. The grid parameter is not expected to change.

520 The T\&D grid power loss estimates for India show significant improvements in parallel, leading to a steep and 521 very substantial decline of losses from around $23 \%$ to $6 \%$ from the year 2010 to 2050 (Fig. 21).

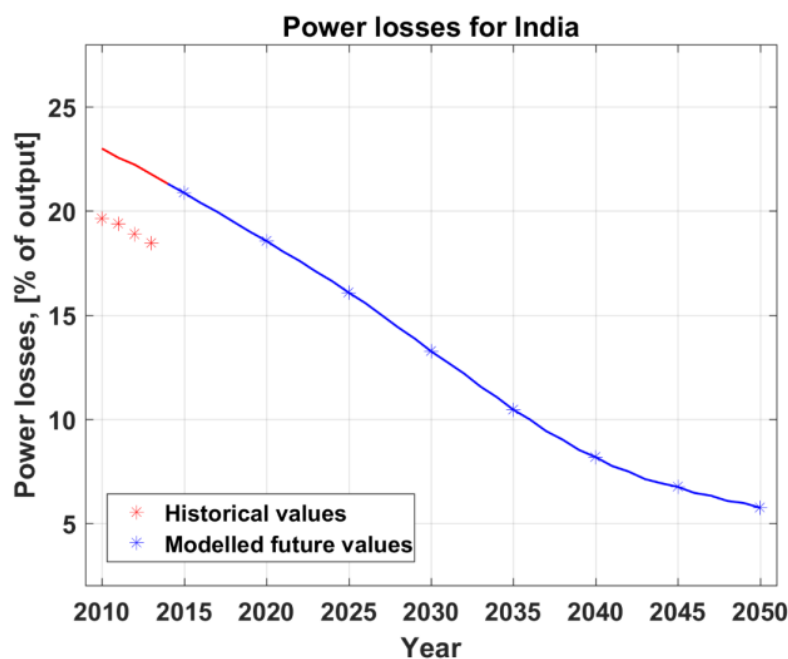

523 Fig. 21. Estimation of T\&D grid power loss in India for the years 2010 to 2050 and with real values for the 524 years 2010 to 2013.

$525 \quad$ Such a rapid decrease can be described by several factors: 

development of the country leads to a value of $36973 € /$ capita.

- As a consequence of the higher GDP per capita, the total grid organization will also have a tendency to improve. It changes by one step.

530 - At the same time CPI goes up from a score of 2.6 to 8.6, which leads step by step to a reduction of 531 electricity theft in Indian power systems.

532 Min and Golden [34] notice, that the political aspect is very important for "technical" parameters such as power 533 loss, since they interpret a lack of efficiency to errors in billing systems, questionable legality of user connections 534 and falsifications in electricity meter operation. In addition, Min and Golden claim that their results suggest that a part of line losses can be explained by political motivations rather than only by technical and economic factors. development level of the respective grid infrastructure, i.e. considerable diminution of the power loss value indicates substantial progress in the structure of a power system in a whole.

539 It is unlikely to achieve continued economic growth without applying some measures and reforms. The 540 example of Karnataka, an Indian state, documents the potential of improvements [35]: After power sector reforms, 541 power losses have decreased from $37.3 \%$ in $1999-2000$ to $11.5 \%$ in $2014-2015$, also driven by an increase in 542 electricity consumption. This clearly confirms that improvements in power sector management are beneficial for 543 a country. Lowering power losses by applying modernisations in the power system while increasing power supply 544 leads to substantial benefits.

\section{$545 \quad$ 5. Conclusion}

546 It has been shown in this article that it is feasible to link several major observable features in a way that is 547 possible to describe T\&D grid power loss in a sufficient and highly accuracy manner for all countries globally. 548 All observable features are parameters which are accessible for countries all over the world, and all of them showed some trends in the data for the accessible power loss data. Some parameters are indirectly expressed by other parameters so that it was possible to substitute them, such as the absolute number of the population. area of a country, the urbanization level, the amount of days with temperature higher than $20^{\circ} \mathrm{C}$ and a parameter representing the organizational level of the grids in a country. The T\&D grid power loss function for all countries globally could be analytically determined on a level of $\mathrm{R}^{2}=0.93$ and a very narrow residual error distribution. 

levels and CPI, has a direct impact on the accuracy of the projections. strong impact on the power loss function. However, already highly developed countries can hardly improve their $\mathrm{T} \& \mathrm{D}$ grid power loss level since they are already very close to the technical limits. countries globally for the current status and the future development on the basis of only a few easily accessible parameters for the country.

\section{Acknowledgements}

The authors gratefully acknowledge the public financing of Tekes, the Finnish Funding Agency for Innovation, for the "Neo-Carbon Energy" project under the number 40101/14. Thanks to the anonymous reviewers for their valuable comments.

\section{Appendix A. Supplementary material}

Supplementary materials associated with this article can be found, in the online version, at:

570

571

572

\section{References}

[1] Soma Shekara Sreenadh Reddy Depuru, L. Wang, V. Devabhaktuni, "Electricity theft: Overview, issues, prevention and a smart meter based approach to control theft," Energy Policy, vol.39, issue 2, pp. 10071015, February 2011.

[2] E. Lakervi and E.J. Holmes, Electricity Distribution Network Design, 2nd ed., London: The Institution of Engineering and Technology, 2003.

[3] N. Amemiya, Q. Lia, R. Nishino, K. Takeuchi, T. Nakamura, K. Ohmatsu, M. Ohya, O. Maruyama, T. Okuma, T. Izumi, "Lateral critical current density distributions degraded near edges of coated conductors through cutting processes and their influence on ac loss characteristics of power transmission cables," Physica C: Superconductivity and its Applications, vol. 471, issues 21-22, pp. 990-994, November 2011.

[4] M. S. Bhalla, "Transmission and Distribution Losses (Power)," in Proc. National Conference on Regulation in infrastructure Services: progress and way forward, New Delhi, Nov. 14-15, 2000.

[5] IEC. International Electrotechnical Commission, "Efficient electrical energy transmission and distribution," International Electrotechnical Commission, Geneva, Switzerland, 2007. 
[6] J. P. Navani, N. K. Sharma, Sonal Sapra, "Technical and Non-Technical Losses in Power System and Its Economic Consequence in Indian Economy," International Journal of Electronics and Computer Science Engineering, vol.1, pp. 757-761, 2012.

[7] A. Vishwakarma, A. Nema, S. Sangle, "Study of determinants of proactive environmental strategies in India's power sector," Journal of Cleaner Production, 194, pp. 43-53, 2018.

[8] C. Hsiaoa, C. Liua, D. Changb, C. Chen, "Dynamic modeling of the policy effect and development of electric power systems: A case in Taiwan,” Energy Policy, 122, pp. 377-387, 2018.

[9] D. Bogdanov and Ch. Breyer, "North-East Asian Super Grid for 100\% renewable energy supply: Optimal mix of energy technologies for electricity, gas and heat supply options," Energy Conversion and Management, 112, 176-190, 2016.

[10] P. Balachennaiah, M. Suryakalavathi, P. Nagendra, "Firefly algorithm based solution to minimize the real power loss in a power system,” Ain Shams Engineering Journal, 9, pp. 89-100, 2018.

[11] Z. Yang, H. Zhong, Q. Xia, C. Kang, “A novel network model for optimal power flow with reactive power and network losses," Electric Power Systems Research, 144, pp. 63-71, 2017.

[12] O. M. Bamigbola, M. M. Ali, M. O. Oke, "Mathematical modelling of electric power flow and the minimization of power losses on transmission lines," Applied Mathematics and Computation, 241, pp. 214$221,2014$.

602

[14] G. Chaojun, D. Yang, P. Jirutitijaroen, W.M. Walsh and T. Reindl, "Spatial Load Forecasting With Communication Failure Using Time-Forward Kriging,” IEEE Transactions on Power Systems, vol. 29, no. 6, pp. 2875-2882, November 2014.

[13] M. T. Costa-Campi, D. Davi-Arderius, E. Trujillo-Baute, "The economic impact of electricity losses," Energy Economics, Eneeco, 2018, doi:10.1016/j.eneco.2018.08.006.

[15] C.A. Dortolina, R. Nardira, "The Loss That is Unknown is No Loss At All: A Top-Down/Bottom-Up Approach for Estimating Distribution Losses," IEEE Transactions on Power Systems, vol. 20, no. 2, pp. 1119-1125, May 2005.

[16] H. Nagayama, "Impacts on investments, and transmission/distribution loss through power sector reforms," Energy Policy, 38, pp. 3453-3467, 2010.

[17] P. Balachennaiah, M. Suryakalavathi M., Palukuru Nagendra, "Optimizing real power loss and voltage stability limit of a large transmission network using firefly algorithm," Engineering Science and Technology, an International Journal, vol. 19, issue 2, pp. 800-810, June 2016. 
614 [18] A. Prieto, B. Prieto, E.M. Ortigosa, E. Ros, F. Pelayo, J. Ortega, I. Rojas, "Neural networks: An overview 615 of early research, current frameworks and new challenges," Neurocomputing, vol. 214, pp. 242-268, 19 $616 \quad$ November 2016.

617 [19] V. E. Gmurman, Manual for task solving in probability theory and statistics, Moscow: Higher school, 1979. 618 [in Russian]

619 [20] World Bank, "Electric power transmission and distribution losses (\% of output)," World Bank, Washington 620 DC, USA [Online]. Available: http://data.worldbank.org/indicator/EG.ELC.LOSS.ZS

[21] IEA. International Energy Agency, "Energy balances for OECD countries (2015 edition)," International Energy Agency, Paris, Paris, $\quad$ France 2015 [Online]. Available: https://www.iea.org/publications/freepublications/publication/EnergyBalancesofOECDcountries2015editio

[22] IEA. International Energy Agency, "World Energy Outlook (2015),” International Energy Agency, Paris, France, 2015 [Online]. Available: http://www.worldenergyoutlook.org/weo2015/

[24] World Bank, "Surface area (sq. km)," World Bank, Washington DC, USA [Online]. Available:

[23] World Bank, “GDP per capita, PPP (current international \$), ' World Bank, Washington DC, USA [Online]. http://data.worldbank.org/indicator/AG.SRF.TOTL.K2

[25] World Bank, "Population density (people per sq. km of land area), “ World Bank, Washington DC, USA [Online]. Available: http://data.worldbank.org/indicator/EN.POP.DNST

[26] UN. United Nations, “Transforming our world: the 2030 Agenda for Sustainable Development," Resolution adopted by the General Assembly, United Nations, New York, USA, Sep. 25, 2015.

[27] UN. United Nations, "World Urbanization Prospects: The 2014 Revision,” United Nations, Department of Economic and Social Affairs, Population Division, New York, USA, 2014 [Online]. Available:

[28] NCEP. National Centers for Environmental Prediction, "Reanalysis data provided by the https://esa.un.org/unpd/wup/ [Online]. Available: http://www.esrl.noaa.gov/psd/ 
643 [30] Transparency International, "Corruption perceptions index 2011," Transparency International, Berlin,

644 Germany [Online]. Available: http://www.transparency.org/cpi2011

645 [31] S. Frank, J. Sexauer, S. Mohagheghi, “Temperature-Dependent Power Flow,” IEEE Transactions on Power 646 Systems, vol. 28, no. 4, pp. 4007-4018, November 2013.

647 [32] A.J. Urquhart, M. Thomson, "Impacts of Demand Data Time Resolution on Estimates of Distribution System

648 Energy Losses,” IEEE Transactions on Power Systems, vol. 30, no. 3, pp. 1483-1491, May 2015.

649 [33] T.B. Smith, "Electricity theft: a comparative analysis," Energy Policy, vol. 32, issue 18, pp. 2067-2076, $650 \quad$ December 2004

651 [34] B. Min and M. Golden, "Electoral cycles in electricity losses in India," Energy Policy, vol. 65, pp. 619-625, February 2014.

653 [35] L. Rajkumari and K. Gayithri, "Performance Analysis of Karnataka Power Sector in India in the Context of Power Sector Reforms,” Energy Policy, 115, pp. 385-396, 2018. 